\title{
A Young Female with Difficulty in Blood Group Determination
}

\author{
APARNA DAS, ${ }^{1}$ BEHNAZ MOBASHWERA, ${ }^{2}$ GOBINDA BANIK, ${ }^{3}$ MD AZIZUL KAHHAR ${ }^{4}$
}

\begin{abstract}
Cold agglutinin disease (CAD) usually develops as a result of the production of a specific immunoglobulin $M$ auto-antibody directed against the $I / i$ and $H$ antigens, precursors of the $A B H$ and Lewis blood group substances, on red blood cells. Where most of the cases of cold agglutination disease usually present with features of hemolysis, acrocyanosis, respiratory symptoms or fatigue due to anemia, here we report an interesting case of CAD with unusual presentation. This 26 years female came with fever for 10 days,jaundice for two months and failure in blood group determination for blood transfusion for her anemia. The physical examination showed severe pallor, jaundice, hepatosplenomegaly and fundoscopic examination revealed Roth spots, hemorrhages and bilateral papilloedema with otherwise normal neurological examination. Complete blood count revealed severe anemia, spuriously raised MCV and MCHC with raised ESR. Peripheral blood film features were suggestive of autoimmune hemolytic anemia (Cold agglutinin disease). MRI of brain was normal. It further indicates the various manifestation of disease as in here presenting as papilloedema in patients with cold agglutination disease.
\end{abstract}

Keywords: Autoimmune hemolytic anemia, papilloedema, Cold agglutinin disease

\section{Introduction}

Autoimmune hemolytic anemia (AIHA) is a complex process characterized by an immune reaction against red blood cell self-antigens. AIHA is classified into warm and cold reactive antibody types. ${ }^{1}$ Cold agglutinin disease (CAD) has traditionally been classified into a primary or idiopathic type not associated with lymphoma or other diseases and a secondary type accompanied by malignant disease, most often lymphoma. ${ }^{2}$ The term "cold" is primarily derived from the immune biology of CAD, not from clinical features of patients. The autoantibodies responsible for hemagglutination at low temperatures, cold agglutinins (CA), bind to erythrocyte carbohydrate antigens at a temperature optimum of $0-4^{\circ} \mathrm{C}$. Binding of CA causes agglutination of erythrocytes and the antigen-antibody complex induces complement-mediated hemolysis. Essential clinical manifestations of primary CAD are hemolytic anemia and cold-induced circulatory symptoms. ${ }^{3}$ We report an interesting case of cold agglutinin disease in a patient who presented with hemolytic anemia and bilateral papillodema. The case emphasized various clinical presentation of cold agglutinin disease.

\section{Case summary}

A 26 year female presented with fever for 10 days, jaundice and fatigue for 2 months. She was advised for blood

1. Assoc. Prof., Dept. of Medicine, Dhaka Medical college

2. Post graduate trainee, Dept. of Medicine, Dhaka Medical college

3. Asst. Prof., Dept. of Medicine, Dhaka Medical college

4. Professor, Dept. of Medicine, Dhaka Medical college

Corresponding author: Dr. Aparna Das, Assoc. Prof., Dept. of Medicine, Dhaka Medical College. Email: aparna_0191 @yahoo.com. transfusion but on repeated attempts at local hospitals her blood group could not be determined. She enjoyed good health before this and no history of previous jaundice, Raynaud's phenomenon and other features suggestive of hemolysis during winter were present. None of her family members had suffered from similar symptoms before.

Clinical examination revealed severe pallor, mild jaundice, hepatosplenomegaly and examination of fundus showed, number of Roth's spots, hemorrhages and bilateral papilloedema, without lymphadenopathy or any other evidence of infection.

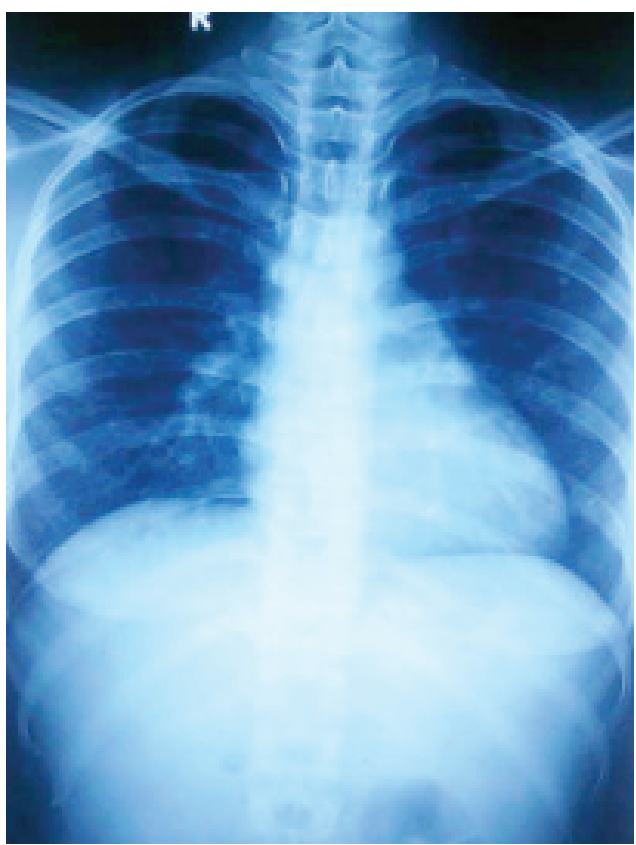

Fig. 1: Radiograph of chest shows no evidence of infection. 
The blood count showed: Leukocyte $8.86 \times 10^{9} / \mathrm{L}$, Hemoglobin 2.3gm/dl, MCV-168 fl, MCH-63.9 pg, MCHC$42.6 \mathrm{~g} / \mathrm{dL}$, Platelet count $1.84 \times 10^{9} / \mathrm{L}$, ESR- $85 \mathrm{~mm}$ in $1^{\text {st }}$ hour. PBF showed features suggestive of cold agglutinin disease. Leukocyte- $7.91 \times 10^{9} / \mathrm{L}$, Hemoglobin-3.9gmldL, MCV$122 \mathrm{fl}, \mathrm{RBC}$-reduced in number, plenty of polychromatic cell, nucleated red cell, few spherocytes and reduced agglutination.

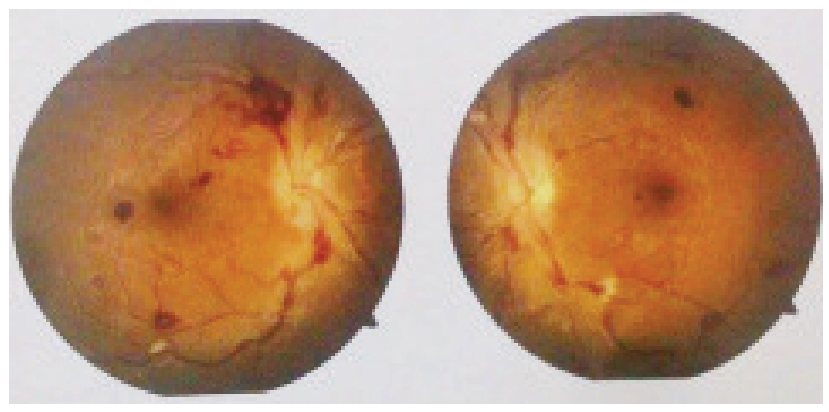

Fig. 2: Fundal photograph showing Roth's spots, hemorrhages and papilloedema.

Direct Coomb's test was positive, reticulocyte count-14\%, serum LDH-2057 IU/L, Vit B12->2000pg/ml, ANAnegative. USG of whole abdomen revealed: Hepatosplenomegaly with no definite intra abdominal lymphadenopathy.

A diagnosis of primary CAD was made. Patient refused to go for bone marrow examination and other investigation workup. She has been started on steroids as she got discharged against medical advice and agreed to follow up after 2 weeks.

\section{Discussion}

The incidence of AIHA is estimated to be approximately $1: 100,000$ in adults. ${ }^{4}$ Among these, warm-reactive antibodies are responsible for $87 \%$ of the cases and cold reactive antibodies are responsible for $13 \%$ of the cases. ${ }^{4}$ Cold agglutinins (CAs) were first described by Landsteiner in 1903. ${ }^{5}$ In warm AIHA, the sequestration mainly occurs in the spleen, in contrast in CAD sequestration occurs primarily in the liver. ${ }^{6}$

Mild, chronic hemolytic anaemia exacerbates in the winter, which is a general rule for CAD. ${ }^{7}$ Acrocyanosis occurs due to the agglutination of cells in the cooler vessels of the hands and feet. The first suspicion of CAD comes from the haematology laboratory's failed attempts to obtain a meaningful RBC count and indices. ${ }^{7}$ The RBC counts are decreased and $\mathrm{MCV}$ is falsely elevated, producing an unbelievably high MCHC. $^{7}$ This problem can be avoided by prewarming the samples to $37^{\circ} \mathrm{C}$ before feeding them into the analyzer. ${ }^{8}$ Bilirubin is mildly elevated and it is rarely more than $3 \mathrm{mg} / \mathrm{dl} .^{7}$ The direct antiglobulin test is positive with polyspecific and anti compliment anti-sera. ${ }^{9}$

Patients with high titres or wide thermal amplitude antibodies can pose extremely difficult serological problems for the blood bank laboratories, which happened in the present case. Often, incompatible units are released due to the residual agglutination from the cold auto-antibody. ${ }^{7}$ These problems can be overcome by washing the patients' cells with warm saline in the direct grouping and by using normal $\mathrm{AB}$ positive serum on the control slide. ${ }^{8}$ The paradox in CAD is the exacerbations that occur during febrile illnesses, which were seen in our patient.The other differential diagnoses which can be considered are paroxsysmal nocturnal haemoglobinuriaand cryoglobulinaemia. ${ }^{6,7}$

In the present case, a 26-year female presented with fever for 10 days and jaundice for 2 months, with hepatomegaly and splenomegaly and hemorrhages, Roth's spots and bilateral papilloedema on fundoscopy without any visual or neurological abnormalities. No history of previous acrocyanosis and no evidence of infection could be established in her case. The haemogram showed erratic values of the RBC count and the blood indices. The peripheral blood smear showed the spontaneous agglutination of RBCs, with normal WBC and platelets. This problem was encountered while the patient's blood group was being determined, due to the spontaneous agglutination on the slide. So, this we report as an unusual presentation of $\mathrm{CAD}$ and was one of the rare cases seen in our settings.

\section{Conclusion}

CAD is not an indolent disease in terms of the major clinical symptoms and the quality of life. The plethora of problems that occur during the laboratory testing of CAD should be known to the pathologist to make an early and accurate diagnosis. We also wish to highlight that there might be uncommon presentations of CAD as in this case papilloedema which couldn't be otherwise demonstrated. Physicians need to keep a high index of suspicion to suspect $\mathrm{CAD}$ with various presentations in such patients. The recent treatment modalities which use rituximab and fludaribine have shown good results, thus emphasizing the need for an early diagnosis of CAD.

\section{Conflict of interest: None}

\section{References}

1. Petz LD, Garratty G. Classification and clinical characteristics of autoimmune hemolytic anemias. In: Petz LD, Garratty G editors. Immune hemolytic anemia. Philadelphia: Churchill Livingstone; 2004:61-131 
2. Ulvestad E, Berentsen S, Bo K, Shammas FV. Clinical immunology of chronic cold agglutinin disease. Eur $\mathrm{J}$ Haematol. 1999;63(4):259-66

3. Nydegger UE, Kazatchkine MD, Miescher PA. Immunopathologic and clinical features of hemolytic anemia due to cold agglutinins. SeminHematol. 1991;28(1):66-77.

4. Powers A, Silberstein LE. Autoimmune Haemolytic Anaemia. In: Hoffman R, Benz EJ, Shattil SJ, Furie B, Silberstein LE, McGlave P, Heslop H, editors. Hematology: Basic Principles and Practice. 5th ed. Philadelphia: Churchill Livingstone; 2008;645-67.
5. Lodi G, Resca D, Reverberi R. Fatal cold agglutinin haemolytic anaemia: a case report. Journal of Medical Case Reports 2010;4:252.

6. Berentsen S, Beiske K, Tjonnfjord GE. Primary chronic cold agglutinin disease: An update on the pathogenesis, clinical features and therapy. Haematology 2007;12(5):361-70.

7. Neff TA. Autoimmune Haemolytic Anaemias. In: Greer JP, Foerster J, Lukens JN, editors. Wintrobe's Clinical Haematology. 11th ed. Philadelphia: Lippincott Williams and Wilkins; 2003;1157-82.

8. Bain BJ, Win N. Acquired haemolytic anaemias. In: Lewis SM, Bain BJ, Bates I, editors. Dacie and Lewis Practical Haematology. 10th ed. Philadelphia: Elsevier; 2006;239-70. 